\title{
Correction to: Evaluation of publication delays in the orthopedic surgery manuscript review process from 2010 to 2015
}

Daniel A. Charen ${ }^{1}$ (D) Nolan A. Maher ${ }^{1}$. Nicole Zubizarreta ${ }^{1} \cdot$ Jashvant Poeran $^{1}$. Calin S. Moucha ${ }^{1} \cdot$ Shai Shemesh ${ }^{2,3}$

Published online: 4 July 2020

(c) Akadémiai Kiadó, Budapest, Hungary 2020

\section{Correction to: Scientometrics} https://doi.org/10.1007/s11192-020-03493-7

In the original publication of the article, the author's name "Shai Shemesh" was missed. The complete author group is given in this Correction.

The original article has been corrected.

The original article can be found online at https://doi.org/10.1007/s11192-020-03493-7.

\section{Daniel A. Charen}

daniel.a.charen@gmail.com

1 Leni and Peter W. May Department of Orthopaedic Surgery, Icahn School of Medicine at Mount Sinai, 5 E 98th St, 9th Fl, New York, NY 10029, USA

2 Department of Orthopaedic Surgery, Rabin Medical Center, Petach Tikva, Israel

3 Sackler Faculty of Medicine, Tel Aviv University, Tel Aviv, Israel 